\title{
Time-dependent gene expression pattern of Listeria monocytogenes J016I in biofilms
}

This article was published in the following Dove Press journal:

Advances in Genomics and Genetics

27 January 2012

Number of times this article has been viewed

\section{Prem Saran Tirumalai Soam Prakash \\ Environmental and Advanced Parasitology Laboratory, Department of Zoology, Faculty of Science, Dayalbagh Educational Institute, Dayalbagh, Agra, India}

Background: Listeria monocytogenes J0161, a food-borne pathogen, forms biofilm on contact surfaces, which makes the bacterium highly resistant. Biofilm formation in vivo confers resistance to antimicrobial agents, and in vitro not only increases resistance but also increases the risk of transmission of the pathogen. Biofilm formation is a complex dynamic process. The mechanism of biofilm formation is not as yet well understood. Understanding the molecular mechanism of biofilm formation will be of significance in removal of biofilms, thereby reducing the risk of transmission.

Methods: L. monocytogenes cultures were grown to form biofilms on glass slides. At time intervals of 4, 12, and 24 hours, the cells were pelleted and the RNA extracted. The extracted RNA was analyzed using microarray technique and statistical tools.

Results: The microarray data showed that gene expression was specifically upregulated at each time interval. About 159, 40, and 184 genes were upregulated at 4, 12, and 24 hours, respectively. An ascending and descending pattern of gene upregulation was identified.

Conclusion: We report specific genes for biofilm growth of L. monocytogenes that were upregulated at particular time intervals. The role of specific genes in the formation of biofilms by L. monocytogenes $\mathrm{J} 0161$ can be studied using these data.

Keywords: Listeria monocytogenes, microarray, biofilms, gene expression

\section{Introduction}

Listeriosis a zoonotic bacterial disease that has emerged as a major food-borne disease during the past two decades, and has a high case fatality rate of approximately $20 \%-30 \%$. ${ }^{1}$ Listeriosis, as an important cause of severe illness accounts for $3.8 \%$ of hospitalizations for food-borne disease and $27.6 \%$ of deaths due to food-borne illness. ${ }^{2}$ The severity of the disease includes meningitis, septicemia, and abortion. The risk of listeriosis is greatest among certain well defined high-risk groups, including pregnant women, neonates, and the elderly, but may occasionally occur in persons who have no predisposing underlying condition. ${ }^{1}$ There have been more than 20 outbreaks of listeriosis in different parts of the globe since 1981, and involving different types of food. ${ }^{3-12}$

The disease is caused by Listeria monocytogenes. The pathogen gains entry into a food-processing facility and survives by forming microbial community niches known as "biofilms". ${ }^{13-15}$ It has been reported that biofilm formation by L. monocytogenes is the major cause of transmission of the pathogen. ${ }^{16}$ Biofilm formation increases the resistance of the pathogen to antimicrobial agents and also increases resistance to environmental stress. ${ }^{17}$ Once established as a biofilm, removal of L. monocytogenes becomes a challenge. ${ }^{18}$ Biofilm formation is a multiphase complex process, starting
Correspondence: Soam Prakash Environmental and Advanced Parasitology Laboratory, Department of Zoology, Faculty of Science, Dayalbagh Educational Institute, Dayalbagh, Agra 282 I I0, India Tel +9| 93 |9| I 2307

$\mathrm{Fax}+9 \mid 562280$ I226

Email prakashsoamdei@gmail.com 
with attachment of a cell to a surface, followed by irreversible adherence, and multiplication and growth to form a threedimensional structure. This phase-wise development of a biofilm is therefore a time-dependent process. Understanding the complexity of the process of biofilm formation has been a long-standing issue. It is believed that understanding of the mechanism behind biofilm formation will yield answers to many intriguing questions, from the very objective and need for biofilm formation by a microbe to ways and means of getting rid or making use of biofilms. ${ }^{19}$ Therefore, it is essential to understand fundamentally the basic phenomenon, in particular the expression of genes that contribute to the formation of biofilm and are otherwise different from laboratory-grown cultures, broth, or a colony.

Here we report on the variations in gene expression of L. monocytogenes and patterns studied by microarray at different time intervals in biofilm formation. We chose to work on the microarray gene expression pattern of the J0161strain of L. monocytogenes, which is a human isolate of serotype $1 / 2 \mathrm{a}$, and this adds to the significance of our study. We report on the genes that were upregulated specifically at 4, 12, and 24 hours.

\section{Materials and methods}

\section{Bacterial strains and culture conditions}

The J0161strain of L. monocytogenes was selected for study because its complete transcriptome was available and annotated in the L. monocytogenes database held at the Broad Institute. Further, amongst the strains that were annotated and for which the transcriptome was available, the J0161 strain had the highest percentage $(78.5 \%)$ of annotated genes (2335 of 2973 gene transcripts).

The J0161 L. monocytogenes strain was obtained from the Agriculture Research Services, United States Department of Agriculture, and grown both in broth and as biofilm. Biofilms were grown as pure culture on three different slides for studying gene expression after set time periods of incubation, ie, at 4,12 , and 24 hours.

A pure culture of L. monocytogenes J0161 was grown in broth as well as biofilm using tryptone soy broth as the growth medium. L. monocytogenes in broth was grown for 24 hours at $37^{\circ} \mathrm{C}$, and as biofilms for 4,12 , and 24 hours at $37^{\circ} \mathrm{C}$ on glass slides. The broth culture was used as a reference/control sample.

The culturing technique used for biofilm formation involved a static batch culture method, in which the experimental setup was incubated without nutrient replenishment at the defined time interval of the study after introducing the inoculum. Static batch cultures of this type have recently been reported to be an excellent method for genetic screening and for understanding the signals that trigger the transition of planktonic cells to form biofilms. ${ }^{20}$

In our earlier experiments to enumerate the cells in biofilms grown using the static batch culture method, we observed a trend of cell count that was typical of a standard growth curve (data not shown), and peaked at 12 hours. The cell count after 12 hours of incubation was fluctuating until 24 hours of incubation. There was a decline in the cell count after 24 hours. A similar pattern was observed by Chavant et al. ${ }^{21}$ Therefore, based on our observation and inferences, we designed our experimental setup to study the gene expression pattern, taking into account the fact that the expression pattern at 4, 12 and 24 hours would depict gene expression at different stages of biofilm formation. We considered 4 hours of incubation as the stage of irreversible attachment, 12 hours as the stage of formation of microcolonies, and 24 hours as the peak stage of fruiting biofilm bodies.

In evaluating the kinetics of biofilm formation, Beresford et $\mathrm{al}^{22}$ had reported the attachment of Listeria cells as early as 2 hours, but our attempts to extract RNA completely at incubation times earlier than 4 hours did not yield the requisite volume (less than $50 \mathrm{ng}$ ) and/or concentration $(<6 \mathrm{ng} / \mu \mathrm{L})$ for downprocessing by microarray. Hence the decision was made to study the expression pattern after 4 hours of incubation at the earliest.

\section{Microarray studies}

\section{RNA extraction and evaluation}

Cells were pelleted after 4, 12, and 24 hours of incubation as biofilms. Similarly, cells in pure culture broth (reference/control) were pelleted after 24 hours of incubation. The pelleted cells were washed with phosphate buffer solution. The cells were then further processed for RNA extraction using a Ribo pure bacteria kit (Ambion ${ }^{\circledR}$, Invitrogen, Carlsbad, CA) according to the manufacturer's instructions. The concentration and purity of the RNA extracted were evaluated using a bioanalyzer (Agilent 2100, Santa Clara, CA), and absorbance readings at $260 \mathrm{~nm}$ and $280 \mathrm{~nm}$ were performed using a Nanodrop spectrophotometer (ThermoScientific 1000, Hudson, NH). The concentration of the RNA extracted was evaluated using the bioanalyzer, while the purity of the RNA extracted was determined using the standard procedure of measuring $\mathrm{A}_{260}$ and $\mathrm{A}_{280}$ on the Nanodrop spectrophotometer. 


\section{Probe and microarray slide design}

An Agilent Listeria monocytogenes $8 \times 15 \mathrm{k}$ (Amadid 030831) custom gene expression microarray designed by Genotypic Technology Pvt Ltd (Bangalore, India) was used for the experiment. The array consists of 15,000 probes of 60 mer length and contains 2973 unique transcripts obtained from the L. monocytogenes database at the Broad Institute.

\section{RNA labeling, amplification and hybridization}

Poly (A)-tails was added to the $3^{\prime}$ end of RNA using an A-plus Poly (A) polymerase tailing kit (Epicentre Biotechnologies, Madison, WI). The samples were then labeled using an Agilent Quick Amp Kit Plus, and 500 ng of polyadenylated RNA was reverse-transcribed using an oligodT primer tagged to the $\mathrm{T} 7$ promoter sequence. The cDNA thus obtained was converted to double-stranded cDNA in the same reaction. Further, the cDNA was converted to cRNA in the in vitro transcription step using T7 RNA polymerase enzyme, and Cy3 dye was added into the reaction mix. During cRNA synthesis, Cy3 dye was incorporated into the newly synthesized strands. The cRNA obtained was purified using Qiagen RNeasy columns. The concentration and amount of dye incorporated was determined using the Nanodrop spectrophotometer. Samples that passed quality control for specific activity were taken for hybridization, and $600 \mathrm{ng}$ of labeled RNA was hybridized on the array.

\section{Hybridization, scanning, and data analysis}

Following amplification, the cRNA was hybridized using the Agilent gene expression hybridization kit in Sure hyb chambers (Agilent) at $65^{\circ} \mathrm{C}$ for 16 hours. The hybridized slides were washed using Agilent gene expression wash buffer. The hybridized washed microarray slides were then scanned on a G2505C scanner (Agilent) and the images were quantified using feature extraction software (version 10.5.1.1, Agilent). The raw data extracted were analyzed using GeneSpring GX version 11.0 software from Agilent. Normalization of the data was done in GeneSpring GX using the 75th percentile shift (percentile shift normalization is a global normalization, where the locations of all the spot intensities in an array are adjusted). This normalization takes each column in an experiment independently, and computes the nth percentile of the expression values for the array across all spots (where $\mathrm{n}$ has a range of $0-100$ and $n=75$ is the median). It subtracts this value from the expression value of each entity normalized to specific control samples. Significant genes upregulated and downregulated by at least one-fold within the samples with respect to the control sample were identified. Differentially regulated genes were clustered using hierarchical clustering based on the Pearson coefficient correlation algorithm to identify significant gene expression patterns (the clustering algorithm measures the similarity or difference between genes or conditions).

\section{Pathway annotations}

All pathway and gene ontology function data for the available strains of $L$. monocytogenes and the protein sequences for available pathway data were collected from Uniprot. Transcript sequences for L. monocytogenes J0161 were BLASTed against the protein database. All the significant genes showing hits greater than $90 \%$ identity were selected for pathway annotation.

\section{Microarray data accession number}

The microarray data have been deposited and made available at the Gene Expression Omnibus database under the accession number GSE27936 (http://www.ncbi.nlm.nih.gov/geo).

\section{Validation by quantitative PCR}

To validate our microarray data, we performed real-time polymerase chain reaction (PCR) to determine the gene expression pattern of PrfA (LMOG_03055T0), glycoprotein (gp) 49 (LMOG_02949T0), chitinase (LMOG_01358T0), and penicillin-binding protein gene (LMOG_00981T0) at different time points $(4,12$, and 24 hours). Total RNA was extracted from independent biofilm cultures at 4, 12, and 24 hours, respectively, using AM-1925 (Ambion). DNasetreated RNA was used to synthesize cDNA using an Affinity Script quantitative PCR cDNA synthesis kit (Agilent). Relative quantification by quantitative PCR was done using an Invitrogen Power SYBR Green PCR Master Mix. The experiment was conducted using a Stratagene $\mathrm{M} \times 3005 \mathrm{P}$ (Agilent) platform. The sequences and length of the primers used are as shown in Table 1. The relative gene expression levels were determined after normalizing with GAPDH as the reference gene using the Delta CT method.

\section{Results}

The results obtained from the study were analyzed and are shown with the emphasis on understanding the specific genes expressed at a higher level than the reference sample (after 24 hours of broth culture at $37^{\circ} \mathrm{C}$ ) at different stages of biofilm formation. Further, genes showing a gradual increase in upregulation or downregulation at every stage of biofilm 
Table I Forward and reverse primers of target genes for qPCR

\begin{tabular}{llll}
\hline Gene & Primer type & Sequence & Length \\
\hline PrfA & Forward & ATTTAGAAGTCATTAGCGAGCA & 22 \\
& Reverse & CAGGATTAAAAGTTGACCGCA & 21 \\
gp49 & Forward & TTAGAAGAGGCAATGAACATAG & 22 \\
& Reverse & GTTGTTCATTTTGCTGTTCGTT & 22 \\
Chitinase & Forward & GAAGGGAGACGGAGTAAATC & 20 \\
& Reverse & CGAACGCCTGCTCATCCC & 18 \\
Penicillin binding protein gene & Forward & CTATCACTACAGGACTTCGC & 20 \\
& Reverse & CAAGAGCTGTATGAATGGTTAA & 22 \\
\hline
\end{tabular}

formation have been identified. Figure 1 compares variation in the L. monocytogenes J0161 gene expression pattern at different stages of biofilm formation with that of the reference sample at 24 hours of broth culture. Figure 2 is a Venn diagram showing the upregulated genes for the whole transcriptome of L. monocytogenes J0161 at different stages of biofilm

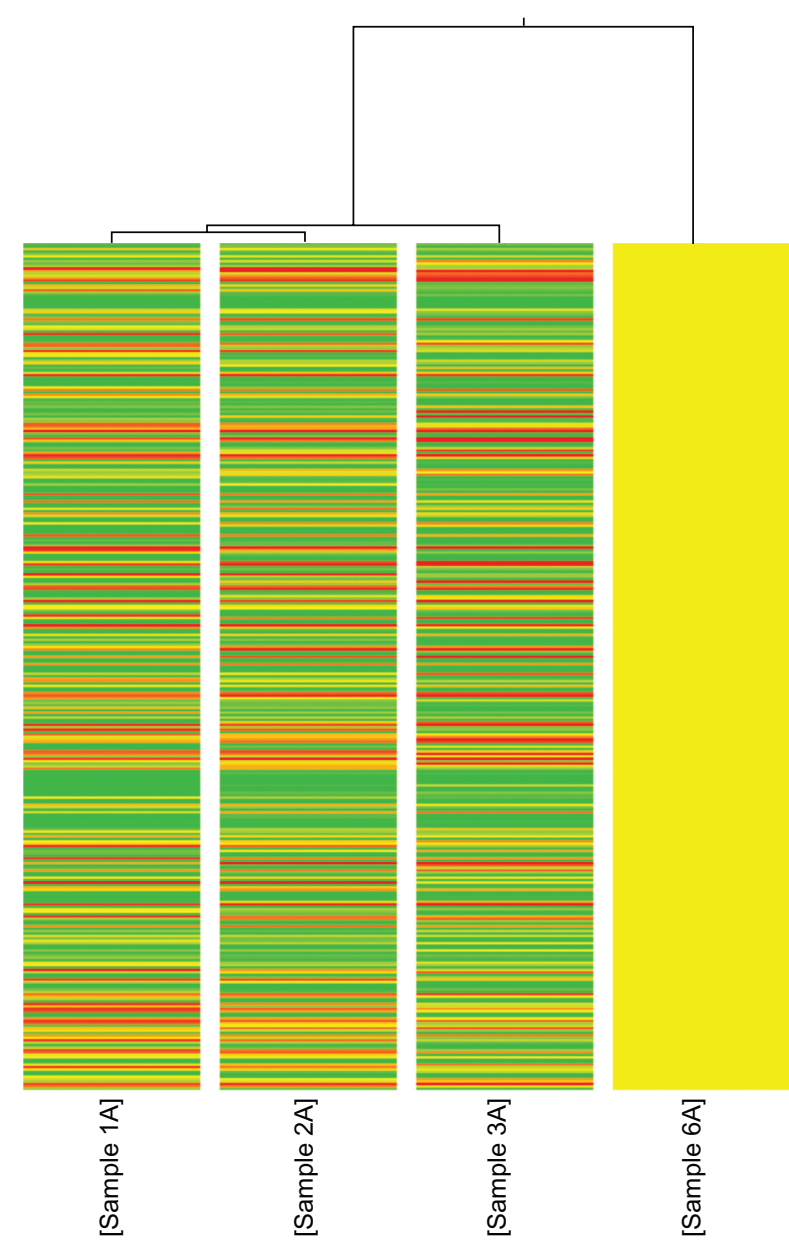

Figure I Microarray results in dendrogram after normalization with the reference. Columns marked as IA, $2 \mathrm{~A}$ and $3 \mathrm{~A}$, represent gene expression as bioflims (of $L$ monocytogenes J0I6I) at 4,12 , and 24 hours respectively. Column marked as 6A is the reference, which is gene expression at 24 hours as broth of $L$ monocytogenes $\mathrm{J} 016 \mathrm{I}$. Notes: Yellow depicts neutral regulation, red depicts upregulation and green depicts downregulation. formation $(4,12$, and 24 hours) and that at 24 hours of broth culture. The diagram compares the genes upregulated at specific intervals of biofilm formation and genes upregulated at all three time intervals of biofilm formation.

\section{Upregulation of genes as a function of time}

More than 150 genes were upregulated after 4 hours of incubation for biofilm formation, three of which showed a more than two-fold upregulation in expression. While two of them are hypothetical protein coding genes (http:/www.broadinstitute.org/annotation/genome/listeria_group/MultiHome. html), the third is a "thioredoxin" gene (LMOG_00491T0) known for its role in the response to oxidative stress. ${ }^{23,24}$ Further analysis of the hypothetical proteins revealed that one of them (LMOG_00557T0) is likely to be involved in oxidationreduction (http://www.uniprot.org/), as shown in Table 2.
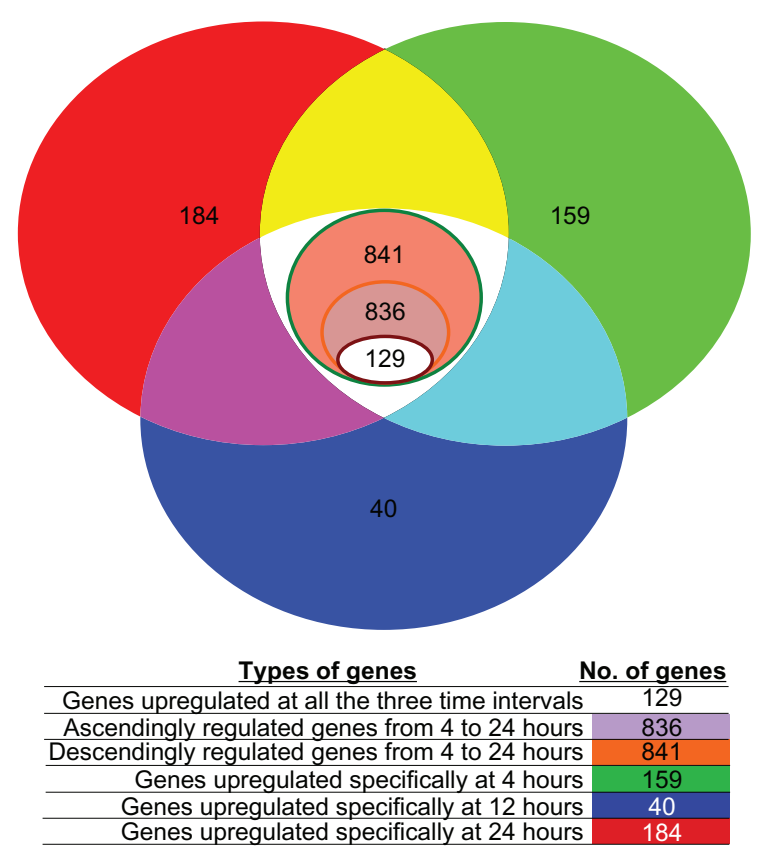

Figure 2 Venn diagram showing the number of genes with a specific pattern of regulation at specified time intervals. 
At 12 hours, the number of upregulated genes decreased to 40 . Three of these 40 genes showed more than a two-fold increase in expression, with the "M protein transacting positive regulator" (LMOG_01126T0) showing at least a three-fold increase in expression. The other two genes were PTS system galactitol-specific enzyme IIB component (LMOG_01128T0) and a hypothetical protein (LMOG_02496T0), as shown in Table 3.

After 24 hours of incubation for biofilm formation, more than 150 genes were upregulated, of which 24 were showing more than two-fold gene expression. Among the 24 genes that showed more than two-fold gene expression, nine were glycoprotein genes, ie, $g p 43,11,37,39,15,44,63$, and 22 (LMOG_03098T0, LMOG_03129T0, LMOG_03097T0, LMOG_03100T0, LMOG_03133T0, LMOG_03099T0, LMOG_03115T0, and LMOG_03140T0, respectively), while five of them were hypothetical protein genes (Table 4).

Our results show incremental upregulation of genes over time. Apart from the transcripts that were specifically upregulated at a particular time interval, a total of 836 genes showed a gradual increase in expression with time (from 4 to 24 hours of incubation). Further, there were variations in the expression levels among these genes. A significant upregulation of at least six-fold in the expression of gp49 (LMOG_03104T0) was observed at 4-24 hours, while 8, 20, and 44 genes were upregulated by five-fold, four-fold, and three-fold, respectively. Proteins of the glycoprotein family comprised the majority of the transcripts prominently exhibiting this trend (Tables 5 and 6 ). More than $70 \%$ of the genes downregulated at 4-24 hours of incubation were related to sugar metabolism and transport (Tables 7 and 8). Sets of 129 transcripts were upregulated at incubation time intervals of 4,12 , and 24 hours as biofilms (Table 9). It is noteworthy that these genes were upregulated only during growth as biofilms but not in broth.

Quantitative PCR was done on PrfA (LMOG_03055T0), gp49 (LMOG_02949T0), chitinase (LMOG_01358T0), and penicillin-binding protein gene (LMOG_00981T0) genes to validate the expression pattern observed using the microarray data. In the microarray data, genes for both PrfA and chitinase showed a trend of descending regulation over time, while the genes for $g p 49$ and penicillin-binding protein gene showed an incremental pattern of expression. The quantitative PCR data for the target genes showed a similar pattern of expression to that observed in the microarray data (Figures 3, 4, 5, and 6).

\section{Discussion}

Biofilm formation is a multiphase dynamic process, beginning from the stage of initial attachment to its development and dispersion. Cells in the biofilm formation stage are different from culture-grown planktonic cells. ${ }^{15}$ When a microbial culture is introduced into a medium, the bacterial cells adhere to the available contact surface, eventually forming an irreversible attachment. Thereafter, the cells grow in number to develop into a mature biofilm. Fully formed/ mature biofilms, which are often multilayered structures, burst to disperse cells from within the biofilm. These dispersed cells, in turn, settle down at remote sites on a contact surface and develop further into independent biofilm. Despite the enormous amount of data available on biofilm physiology, the molecular level dynamics governing the various stages of biofilm development are not well understood. Given the phenotypic differences between biofilms and planktonic cells, the metabolic pathways and gene expression of the sessile biofilm cells are likely to be different. Using microarrays, Yi et $\mathrm{al}^{25}$ have reported on the role of a particular regulatory protein in biofilm formation by yeasts. In this study, we have analyzed time-dependent gene expression data to delineate the probable role of genes at different stages of biofilm formation.

Several earlier studies have reported such time-dependent expression. Hautefort et $\mathrm{al}^{26}$ have reported simultaneous time-dependent expression of three type 3 secretion systems in Salmonella enterica. In another study, Chan et $\mathrm{a}^{27}$ have shown differential gene expression at fixed time intervals (log and stationary phases) of $L$. monocytogenes growth when cultured in broth at $4^{\circ} \mathrm{C}$ and $37^{\circ} \mathrm{C}$ under given conditions. However, there are no studies directed towards understanding the time-dependent gene expression pattern of L. monocytogenes in biofilm. For the first time, we have demonstrated specific genes that are upregulated or overexpressed and downregulated or poorly expressed during particular stages of biofilm growth. We have also tried to ascertain the generic function of genes active at a particular stage of biofilm formation. To represent the gene expression pattern, we have used L. monocytogenes J0161 gene expression over 24 hours in broth culture as a reference.

As compared with L. monocytogenes J0161 gene expression after 24 hours of broth culture, about 159 gene transcripts were specifically upregulated after 4 hours of biofilm formation. Upregulation by more than two-fold was observed in only three of the total number of genes upregulated, and among them were two gene transcripts that were related to oxidative stress at hour 4 of incubation. Oxidative stress in biofilm has been directly linked to diversity within the biofilm in Pseudomonas aeruginosa. ${ }^{28}$ The mechanism of 
Table 2 List of genes and their annotations upregulated at 4 hours of incubation as biofilms

\begin{tabular}{|c|c|c|c|c|}
\hline S no & Gene & $\begin{array}{l}\text { Fold expression } \\
\text { values }\end{array}$ & $\begin{array}{l}\text { No of gene } \\
\text { transcripts }\end{array}$ & Annotations \\
\hline I & LMOG_00557T0 & 2.3 & 3 & Hypothetical protein \\
\hline 2 & LMOG_0049IT0 & 2.1 & & Thioredoxin \\
\hline 3 & LMOG_02373T0 & 2.0 & & Hypothetical protein \\
\hline 4 & LMOG_0I789T0 & 2.0 & 92 & Hypothetical protein \\
\hline 5 & LMOG_01659T0 & 2.0 & & Thioredoxin \\
\hline 6 & LMOG_0I058T0 & 1.9 & & Hypothetical protein \\
\hline 7 & LMOG_01215T0 & 1.9 & & Cold shock protein CspB \\
\hline 8 & LMOG_0I36IT0 & 1.8 & & Ribonuclease $\mathrm{HI}$ \\
\hline 9 & LMOG_00723T0 & 1.8 & & Hypothetical protein \\
\hline 10 & LMOG_007I6T0 & 1.8 & & YkuJ protein \\
\hline II & LMOG_00589T0 & 1.8 & & Glyoxalase \\
\hline 12 & LMOG_0I063T0 & 1.7 & & Ribonucleotide reductase-associated flavodoxin \\
\hline 13 & LMOG_0I728T0 & 1.7 & & Cellobiose-specific PTS system IIA component \\
\hline 14 & LMOG_0275IT0 & 1.7 & & Adenylosuccinate lyase \\
\hline 15 & LMOG_0I776T0 & 1.7 & & 6-phosphogluconolactonase \\
\hline 16 & LMOG_01615T0 & 1.7 & & Cytochrome aa3 quinol oxidase subunit IV \\
\hline 17 & LMOG_02706T0 & 1.6 & & Hypothetical protein \\
\hline 18 & LMOG_00859T0 & 1.5 & & Transcriptional regulator \\
\hline 19 & LMOG_0I707T0 & 1.5 & & Catalase \\
\hline 20 & LMOG_02774T0 & 1.4 & & Hypothetical protein \\
\hline 21 & LMOG_0I796T0 & 1.4 & & Hypothetical protein \\
\hline 22 & LMOG_0I729T0 & 1.4 & & ROK family protein \\
\hline 23 & LMOG_0I748T0 & 1.4 & & General stress protein 26 \\
\hline 24 & LMOG_02173T0 & 1.3 & & Phospholipase/carboxylesterase \\
\hline 25 & LMOG_02549T0 & 1.3 & & Maltose/maltodextrin transport ATP-binding protein MalK \\
\hline 26 & LMOG_00928T0 & 1.3 & & Carbonic anhydrase \\
\hline 27 & LMOG_00980T0 & 1.3 & & Hypothetical protein \\
\hline 28 & LMOG_01932T0 & 1.3 & & Hypothetical protein \\
\hline 29 & LMOG_0I799T0 & 1.3 & & Oxidoreductase \\
\hline 30 & LMOG_00343T0 & 1.3 & & Cold shock protein CspB \\
\hline 31 & LMOG_00429T0 & 1.3 & & Succinyl-CoA synthetase \\
\hline 32 & LMOG_03I95T0 & 1.3 & & Pyridine nucleotide-disulfide oxidoreductase \\
\hline 33 & LMOG_024I3T0 & 1.3 & & Preprotein translocase SecG subunit \\
\hline 34 & LMOG_0284IT0 & 1.3 & & Hypothetical protein \\
\hline 35 & LMOG_01669T0 & 1.3 & & Hypothetical protein \\
\hline 36 & LMOG_02457T0 & 1.3 & & FeS assembly protein SufB \\
\hline 37 & LMOG_0088IT0 & 1.3 & & Hypothetical protein \\
\hline 38 & LMOG_00965T0 & 1.3 & & Glyoxalase \\
\hline 39 & LMOG_028I3T0 & 1.3 & & Hypothetical protein \\
\hline 40 & LMOG_00I26T0 & 1.3 & & FxsA \\
\hline 41 & LMOG_03зІ0T0 & 1.3 & & Methionine-R-sulfoxide reductase \\
\hline 42 & LMOG_0I767T0 & 1.3 & & HAD-superfamily hydrolase \\
\hline 43 & LMOG_03193T0 & 1.3 & & Hypothetical protein \\
\hline 44 & LMOG_03055T0 & 1.3 & & Virulence regulatory factor PrfA \\
\hline 45 & LMOG_00673T0 & 1.2 & & Molybdenum cofactor biosynthesis protein B \\
\hline 46 & LMOG_02319T0 & 1.2 & & Serine hydroxymethyltransferase \\
\hline 47 & LMOG_02232T0 & 1.2 & & Sulfate transporter \\
\hline 48 & LMOG_00834T0 & 1.2 & & Phosphoserine phosphatase rsbX \\
\hline 49 & LMOG_00749T0 & 1.2 & & Esterase \\
\hline 50 & LMOG_02014T0 & 1.2 & & Peptidoglycan binding protein \\
\hline 51 & LMOG_01697T0 & 1.2 & & Phosphosugar-binding transcriptional regulator \\
\hline 52 & LMOG_0067IT0 & 1.2 & & Hypothetical protein \\
\hline 53 & LMOG_02538T0 & 1.2 & & Two-component system response regulator \\
\hline 54 & LMOG_030I5T0 & 1.2 & & Hypothetical protein \\
\hline 55 & LMOG_02092T0 & 1.2 & & Hypothetical protein \\
\hline 56 & LMOG_0II99T0 & 1.2 & & Yggt family protein \\
\hline
\end{tabular}


Table 2 (Continued)

\begin{tabular}{|c|c|c|c|c|}
\hline S no & Gene & $\begin{array}{l}\text { Fold expression } \\
\text { values }\end{array}$ & $\begin{array}{l}\text { No of gene } \\
\text { transcripts }\end{array}$ & Annotations \\
\hline 57 & LMOG_0222IT0 & 1.2 & & Transcriptional regulator \\
\hline 58 & LMOG_02393T0 & I.I & & NADPH dehydrogenase NamA \\
\hline 59 & LMOG_00954T0 & I.I & & Hypothetical protein \\
\hline 60 & LMOG_00829T0 & I.I & & Hypothetical protein \\
\hline 61 & LMOG_02637T0 & I.I & & Hypothetical protein \\
\hline 62 & LMOG_00750T0 & I.I & & Acetyltransferase \\
\hline 63 & LMOG_03030T0 & I.I & & Cysteine synthase $A$ \\
\hline 64 & LMOG_00650T0 & I.I & & Hypothetical protein \\
\hline 65 & LMOG_00080T0 & I.I & & Hypothetical protein \\
\hline 66 & LMOG_02827T0 & I.I & & Hypothetical protein \\
\hline 67 & LMOG_0I064T0 & I.I & & Thioredoxin \\
\hline 68 & LMOG_00272T0 & I.I & & Proton-coupled thiamine transporter YuaJ \\
\hline 69 & LMOG_00007T0 & I.I & & I,4-dihydroxy-2-naphthoate octaprenyltransferase \\
\hline 70 & LMOG_0260IT0 & I.I & & Glutamyl-tRNA synthetase \\
\hline 71 & LMOG_02324T0 & I.I & & ATP synthase subunit $A$ \\
\hline 72 & LMOG_02080T0 & I.I & & Acetyltransferase \\
\hline 73 & LMOG_0II59T0 & I.I & & Chaperonin GroL \\
\hline 74 & LMOG_03033T0 & I.I & & ATP-dependent metalloprotease FtsH \\
\hline 75 & LMOG_00I44T0 & I.I & & Valyl-tRNA synthetase \\
\hline 76 & LMOG_00787T0 & I.I & & Peroxide resistance protein $\mathrm{Dpr}$ \\
\hline 77 & LMOG_0I502T0 & I.I & & Lipase \\
\hline 78 & LMOG_00466T0 & I.I & & Hypothetical protein \\
\hline 79 & LMOG_00068T0 & I.I & & Dipeptidase PepV \\
\hline 80 & LMOG_02678T0 & I.I & & Alpha-mannosidase \\
\hline 81 & LMOG_002I9T0 & I.I & & 30 S ribosomal protein $\$ 20$ \\
\hline 82 & LMOG_0I068T0 & I.I & & Hypothetical protein \\
\hline 83 & LMOG_02994T0 & I.I & & Transcriptional regulator \\
\hline 84 & LMOG_0I037T0 & I.I & & Hypothetical protein \\
\hline 85 & LMOG_0268IT0 & I.I & & Fructose-specific IIA PTS system component \\
\hline 86 & LMOG_008I4T0 & I.I & & Cellobiose-specific PTS system IIB component \\
\hline 87 & LMOG_0I393T0 & I.I & & Manganese-binding lipoprotein mntA \\
\hline 88 & LMOG_02095T0 & 1.0 & & Transcriptional regulator \\
\hline 89 & LMOG_008I3T0 & 1.0 & & IIC component PTS system \\
\hline 90 & LMOG_0I434T0 & 1.0 & & Acyl carrier protein \\
\hline 91 & LMOG_0I007T0 & 1.0 & & Hypothetical protein \\
\hline 92 & LMOG_0I004T0 & 1.0 & & Hypothetical protein \\
\hline 93 & LMOG_032I6T0 & 1.0 & & General stress protein 13 \\
\hline 94 & LMOG_0043IT0 & 1.0 & & Aldose epimerase \\
\hline 95 & LMOG_003 60T0 & 1.0 & 64 & Glycine cleavage system T protein \\
\hline 96 & LMOG_00624T0 & 1.0 & & Monooxygenase \\
\hline 97 & LMOG_0I803T0 & 1.0 & & Dihydroxyacetone kinase $L$ subunit \\
\hline 98 & LMOG_0I63IT0 & 1.0 & & DNA polymerase III beta subunit \\
\hline 99 & LMOG_0I730T0 & 1.0 & & Cellobiose-specific PTS system IIC component \\
\hline 100 & LMOG_0I377T0 & 1.0 & & Hemolysin-3 \\
\hline 101 & LMOG_02218T0 & 1.0 & & Thermostable carboxypeptidase I \\
\hline 102 & LMOG_03160T0 & 1.0 & & Hypothetical protein \\
\hline 103 & LMOG_0304IT0 & 1.0 & & Peptidyl-tRNA hydrolase \\
\hline 104 & LMOG_0I834T0 & 1.0 & & Transcriptional regulator \\
\hline 105 & LMOG_0II67T0 & 1.0 & & MOSC domain-containing protein \\
\hline 106 & LMOG_02679T0 & 1.0 & & Fructose-specific PTS system fructose-specific II component \\
\hline 107 & LMOG_00257T0 & 1.0 & & Transmembrane protein \\
\hline 108 & LMOG_0I358T0 & 1.0 & & Chitinase \\
\hline 109 & LMOG_00743T0 & 1.0 & & Glutathione peroxidase \\
\hline 110 & LMOG_00994T0 & 1.0 & & Hypothetical protein \\
\hline III & LMOG_0I952T0 & 1.0 & & Mannose-specific PTS system IID component \\
\hline 112 & LMOG_02094T0 & 0.9 & & Acetyltransferase \\
\hline
\end{tabular}

(Continued) 
Table 2 (Continued)

\begin{tabular}{|c|c|c|c|c|}
\hline S no & Gene & $\begin{array}{l}\text { Fold expression } \\
\text { values }\end{array}$ & $\begin{array}{l}\text { No of gene } \\
\text { transcripts }\end{array}$ & Annotations \\
\hline 113 & LMOG_00329T0 & 0.9 & & 6-phosphogluconate dehydrogenase \\
\hline 114 & LMOG_02252T0 & 0.9 & & Hypothetical protein \\
\hline 115 & LMOG_00998T0 & 0.9 & & Hypothetical protein \\
\hline 116 & LMOG_0I839T0 & 0.9 & & PTS system IIA 2 domain-containing protein \\
\hline 117 & LMOG_0082IT0 & 0.9 & & Phosphoglycerate mutase \\
\hline 118 & LMOG_0I699T0 & 0.9 & & Hypothetical protein \\
\hline 119 & LMOG_0I797T0 & 0.9 & & Recombination protein RecR \\
\hline 120 & LMOG_03303T0 & 0.9 & & UTP-glucose-I-phosphate uridylyltransferase \\
\hline 121 & LMOG_0I024T0 & 0.9 & & Competence negative regulator mecA \\
\hline 122 & LMOG_00479T0 & 0.9 & & Phosphoglycerate mutase \\
\hline 123 & LMOG_02332T0 & 0.9 & & ATP synthase FI epsilon subunit \\
\hline 124 & LMOG_01692T0 & 0.9 & & Oxidoreductase \\
\hline 125 & LMOG_0I858T0 & 0.9 & & Transcriptional antiterminator \\
\hline 126 & LMOG_0200IT0 & 0.9 & & Lacl family transcription regulator \\
\hline 127 & LMOG_00748T0 & 0.9 & & Branched-chain amino acid aminotransferase \\
\hline 128 & LMOG_0I947T0 & 0.9 & & Amino acid permease \\
\hline 129 & LMOG_02435T0 & 0.9 & & Hypothetical protein \\
\hline 130 & LMOG_00444T0 & 0.9 & & $\mathrm{rnhB}$ \\
\hline 131 & LMOG_00769T0 & 0.9 & & IIm protein \\
\hline 132 & LMOG_0I087T0 & 0.9 & & APC family amino acid-polyamine-organocation transporter \\
\hline 133 & LMOG_0169IT0 & 0.9 & & $\mathrm{~N}$-acetylmannosamine-6-phosphate 2-epimerase \\
\hline 134 & LMOG_03200T0 & 0.9 & & 4-hydroxybenzoyl-CoA thioesterase domain-containing protein \\
\hline 135 & LMOG_00987T0 & 0.9 & & Hypothetical protein \\
\hline 136 & LMOG_02680T0 & 0.9 & & Fructose-specific PTS system IIB component \\
\hline 137 & LMOG_0I478T0 & 0.9 & & Acetyltransferase \\
\hline 138 & LMOG_0042IT0 & 0.9 & & Glycerophosphoryl diester phosphodiesterase \\
\hline 139 & LMOG_01624T0 & 0.9 & & Spermidine $\mathrm{NI}$-acetyltransferase \\
\hline 140 & LMOG_03027T0 & 0.9 & & DNA-directed RNA polymerase delta subunit \\
\hline |4| & LMOG_0I094T0 & 0.9 & & Maltose/maltodextrin $\mathrm{ABC}$ transporter \\
\hline 142 & LMOG_00797T0 & 0.9 & & Membrane protein \\
\hline 143 & LMOG_0I802T0 & 0.9 & & Dihydroxyacetone kinase phosphotransfer subunit \\
\hline 144 & LMOG_00I58T0 & 0.8 & & Glycerol kinase \\
\hline 145 & LMOG_00167T0 & 0.8 & & Preprotein translocase \\
\hline 146 & LMOG_0I870T0 & 0.8 & & Heptaprenyl diphosphate synthase component I \\
\hline 147 & LMOG_0II48T0 & 0.8 & & M22 family peptidase \\
\hline 148 & LMOG_00I24T0 & 0.8 & & 6-phosphofructokinase \\
\hline 149 & LMOG_0I255T0 & 0.8 & & Hypothetical protein \\
\hline 150 & LMOG_00352T0 & 0.8 & & Translation elongation factor $P$ \\
\hline 151 & LMOG_0II62T0 & 0.8 & & Hypothetical protein \\
\hline 152 & LMOG_01618T0 & 0.8 & & Quinol oxidase AA3 \\
\hline 153 & LMOG_0256IT0 & 0.8 & & Phosphoglycerate mutase \\
\hline 154 & LMOG_025I7T0 & 0.8 & & Hypothetical protein \\
\hline 155 & LMOG_028I9T0 & 0.8 & & Methionine aminopeptidase type I \\
\hline 156 & LMOG_0I2I3T0 & 0.8 & & PAP2 family protein \\
\hline 157 & LMOG_0I842T0 & 0.8 & & Galactitol-specific PTS enzyme IIC component \\
\hline 158 & LMOG_01956T0 & 0.8 & & Hypothetical protein \\
\hline 159 & LMOG_00953T0 & 0.8 & & Intracellular protease I \\
\hline
\end{tabular}

diversity caused by oxidative stress is attributed to doublestranded DNA breaks that cause breaks in the whole genome and repair thereafter, leading to mutagenic variants. ${ }^{23}$ Oxidative stress has also been attributed to increased antibiotic resistance in P. aeruginosa. Even though we could not observe any discernible increase in antibiotic resistance in terms of related gene expression patterns from our data, two oxidative stress genes showing the highest upregulation further corroborate earlier established links between oxidative stress and biofilm physiology. prfA (positive [virulence] regulator factor) is another gene of significance that we observed to be upregulated, specifically at hour 4 of incubation. Lemon et a ${ }^{29}$ have suggested that prfA positively regulates biofilm formation. The expression of $p r f \mathrm{~A}$ increased 
Table 3 List of genes and their annotations upregulated at 12 hours of incubation as biofilms

\begin{tabular}{|c|c|c|c|c|}
\hline S no & Gene & $\begin{array}{l}\text { Fold expression } \\
\text { values }\end{array}$ & $\begin{array}{l}\text { No of gene } \\
\text { transcripts }\end{array}$ & Annotations \\
\hline I & LMOG_0II26T0 & 3.4 & 1 & M protein trans-acting positive regulator \\
\hline 2 & LMOG_0II28T0 & 2.7 & 2 & PTS system galactitol-specific enzyme IIB component \\
\hline 3 & LMOG_02496T0 & 2.7 & & Hypothetical protein \\
\hline 4 & LMOG_0II27T0 & 1.7 & 15 & PTS system galactitol-specific enzyme IIA component \\
\hline 5 & LMOG_02429T0 & 1.7 & & Glyoxalase/bleomycin resistance protein/dioxygenase \\
\hline 6 & LMOG_00058T0 & 1.6 & & Indole-3-glycerol phosphate synthase \\
\hline 7 & LMOG_02409T0 & 1.5 & & Phosphopyruvate hydratase \\
\hline 8 & LMOG_02376T0 & $\mathrm{I} .4$ & & Hypothetical protein \\
\hline 9 & LMOG_0II32T0 & $\mathrm{I} .4$ & & Hypothetical protein \\
\hline 10 & LMOG_0I556T0 & 1.3 & & Hypothetical protein \\
\hline II & LMOG_00585T0 & 1.3 & & Propanediol utilization polyhedral body protein PduU \\
\hline 12 & LMOG_02404T0 & 1.2 & & Transcriptional regulator \\
\hline 13 & LMOG_0II3ITO & 1.2 & & Hypothetical protein \\
\hline 14 & LMOG_0II29T0 & 1.2 & & Galactitol-specific PTS system IIC component \\
\hline 15 & LMOG_02407T0 & 1.1 & & Triosephosphate isomerase \\
\hline 16 & LMOG_02408T0 & 1.1 & & 2,3-bisphosphoglycerate-independent phosphoglycerate mutase \\
\hline 17 & LMOG_00I5IT0 & I.I & & Septum site-determining protein MinC \\
\hline 18 & LMOG_00275T0 & 1.1 & & Osmotically activated L-carnitine/choline $A B C$ transporter \\
\hline 19 & LMOG_0023IT0 & 1.0 & 22 & GatB/Yqey domain-containing protein \\
\hline 20 & LMOG_02I78T0 & 1.0 & & Transcriptional regulator \\
\hline 21 & LMOG_02220T0 & 1.0 & & Glycosyl hydrolase, family 4 \\
\hline 22 & LMOG_0II05T0 & 1.0 & & Bacitracin export ATP-binding protein BceA \\
\hline 23 & LMOG_00328T0 & 0.9 & & Two-component system response regulator \\
\hline 24 & LMOG_0I3IOTO & 0.9 & & 2-heptaprenyl-I,4-naphthoquinone methyltransferase \\
\hline 25 & LMOG_00956T0 & 0.9 & & Hydrolase \\
\hline 26 & LMOG_0I454T0 & 0.9 & & STAS domain-containing protein \\
\hline 27 & LMOG_02302T0 & 0.9 & & Fructose-16-bisphosphate aldolase class II \\
\hline 28 & LMOG_0I059T0 & 0.9 & & Metallo-beta-lactamase \\
\hline 29 & LMOG_00205T0 & 0.9 & & MTA/SAH nucleosidase \\
\hline 30 & LMOG_0I322T0 & 0.9 & & Zn-dependent protease \\
\hline 31 & LMOG_03I79T0 & 0.9 & & YbbK protein \\
\hline 32 & LMOG_02234T0 & 0.8 & & Phosphosugar-binding transcriptional regulator \\
\hline 33 & LMOG_00079T0 & 0.8 & & Glutamyl aminopeptidase \\
\hline 34 & LMOG_00742T0 & 0.8 & & LytTr DNA-binding domain family \\
\hline 35 & LMOG_0I227T0 & 0.8 & & Acetolactate synthase catabolic \\
\hline 36 & LMOG_0I900T0 & 0.8 & & Adenylate kinase \\
\hline 37 & LMOG_02465T0 & 0.8 & & Hypothetical protein \\
\hline 38 & LMOG_00039T0 & 0.8 & & Hypothetical protein \\
\hline 39 & LMOG_0I873T0 & 0.8 & & Sex pheromone cADI \\
\hline 40 & LMOG_02I42T0 & 0.8 & & Internalin \\
\hline
\end{tabular}

by 1.26 -fold at 4 hours and thereafter declined by 0.56 -fold at 12 hours and 0.20 -fold at 24 hours, strongly suggesting that expression of this gene is only necessary in the initial stages of biofilm formation.

At hour 12 of biofilm formation, only about 40 gene transcripts were upregulated. Expression of the upregulated genes except for M-protein transacting factor was less than three-fold. M-protein transacting factor has a probable role in regulation of surface protein expression, and was the only significantly upregulated gene at hour 12 of biofilm formation. At later stages of biofilm formation, cell-cell communication is largely mediated via signal transduction mechanisms, and surface proteins are key players. We speculate that upregulation of a gene involved in expression of surface proteins establishes its role in biofilm cell communication. Further studies involving knockout of these genes will help broaden our understanding of their role(s) in biofilm formation.

In our study, 20 genes showed more than a two-fold increase in expression at 24 hours of biofilm formation. Of these 20 genes, nine were glycoproteins and five were hypothetical proteins. Among the four genes that showed more than a three-fold increase in expression, two were hypothetical proteins, and one was gp43. Apart 
Table 4 List of genes and their annotations upregulated at 24 hours of incubation as biofilms

\begin{tabular}{|c|c|c|c|c|}
\hline S no & Gene & $\begin{array}{l}\text { Fold expression } \\
\text { values }\end{array}$ & $\begin{array}{l}\text { No of gene } \\
\text { transcripts }\end{array}$ & Annotations \\
\hline I & LMOG_0I638T0 & 5.2 & I & Hypothetical protein \\
\hline 2 & LMOG_0I387T0 & 3.5 & 3 & Copper-translocating P-type ATPase \\
\hline 3 & LMOG_03098T0 & 3.1 & & gp43 \\
\hline 4 & LMOG_0I262T0 & 3.1 & & Hypothetical protein \\
\hline 5 & LMOG_024I5T0 & 3.0 & 20 & Carboxylesterase \\
\hline 6 & LMOG_02195T0 & 2.9 & & Magnesium transporter \\
\hline 7 & LMOG_03 I29T0 & 2.6 & & gpII \\
\hline 8 & LMOG_03I57T0 & 2.4 & & Transmembrane protein \\
\hline 9 & LMOG_03097T0 & 2.4 & & gp37 \\
\hline 10 & LMOG_03I00T0 & 2.3 & & $\mathrm{gp} 39$ \\
\hline 11 & LMOG_03095T0 & 2.3 & & Hypothetical protein \\
\hline 12 & LMOG_0I388T0 & 2.3 & & Heavy metal-binding protein \\
\hline 13 & LMOG_03।33T0 & 2.3 & & $\mathrm{gp} 15$ \\
\hline 14 & LMOG_03099T0 & 2.2 & & gp44 \\
\hline 15 & LMOG_03।I9T0 & 2.2 & & Hypothetical protein \\
\hline 16 & LMOG_03102T0 & 2.2 & & Hypothetical protein \\
\hline 17 & LMOG_03II6T0 & 2.2 & & gp64 \\
\hline 18 & LMOG_0I660T0 & 2.1 & & Nitroreductase \\
\hline 19 & LMOG_00387T0 & 2.1 & & YlxR \\
\hline 20 & LMOG_03II5T0 & 2.1 & & gp63 \\
\hline 21 & LMOG_02II4T0 & 2.1 & & Methyltransferase \\
\hline 22 & LMOG_02I00T0 & 2.1 & & Glyoxalase \\
\hline 23 & LMOG_03I40T0 & 2.0 & & gp22 \\
\hline 24 & LMOG_0I46IT0 & 2.0 & & Zinc $A B C$ transporter \\
\hline 25 & LMOG_0I002T0 & 2.0 & 114 & Acetyltransferase \\
\hline 26 & LMOG_0280IT0 & 1.9 & & $\mathrm{ABC}$ transporter ATP-binding protein \\
\hline 27 & LMOG_00254T0 & 1.9 & & Zinc $A B C$ transporter \\
\hline 28 & LMOG_0I450T0 & 1.8 & & Methyltransferase \\
\hline 29 & LMOG_02416T0 & 1.8 & & Ribonuclease R \\
\hline 30 & LMOG_000I4T0 & 1.8 & & Laminin-binding surface protein \\
\hline 31 & LMOG_02807T0 & 1.8 & & Outer surface protein \\
\hline 32 & LMOG_03300T0 & 1.8 & & $\mathrm{~N}$-acetylmuramoyl-L-alanine amidase, family 4 \\
\hline 33 & LMOG_0I386T0 & 1.8 & & YvgZ \\
\hline 34 & LMOG_0I493T0 & 1.8 & & Hypothetical protein \\
\hline 35 & LMOG_03।32T0 & 1.7 & & $\mathrm{gpl} 4$ \\
\hline 36 & LMOG_03I06T0 & 1.7 & & Predicted protein \\
\hline 37 & LMOG_03085T0 & 1.7 & & gp33 \\
\hline 38 & LMOG_02IIITO & 1.7 & & Rrf2 family protein \\
\hline 39 & LMOG_03I0IT0 & 1.7 & & Predicted protein \\
\hline 40 & LMOG_03IIITO & 1.7 & & Hypothetical protein \\
\hline 41 & LMOG_00784T0 & 1.7 & & Late competence protein ComEC \\
\hline 42 & LMOG_03।28T0 & 1.7 & & gp 10 \\
\hline 43 & LMOG_00385T0 & 1.6 & & Translation initiation factor IF-2 \\
\hline 44 & LMOG_0I448T0 & 1.6 & & Hypothetical protein \\
\hline 45 & LMOG_00438T0 & 1.6 & & Tyrosine recombinase XerC \\
\hline 46 & LMOG_00I35T0 & 1.6 & & Primosomal protein Dnal \\
\hline 47 & LMOG_0I359T0 & 1.6 & & SSU ribosomal protein SI $4 \mathrm{p}$ \\
\hline 48 & LMOG_02803T0 & 1.6 & & Helicase domain-containing protein \\
\hline 49 & LMOG_00253T0 & 1.6 & & Zinc $A B C$ transporter \\
\hline 50 & LMOG_03।27T0 & 1.5 & & gp9 \\
\hline 51 & LMOG_02768T0 & 1.5 & & Glutamyl-tRNA(GIn) amidotransferase (chain C) \\
\hline 52 & LMOG_00450T0 & 1.5 & & Trigger factor tig \\
\hline 53 & LMOG_0I426TO & 1.5 & & DAK2 domain-containing protein \\
\hline 54 & LMOG_0I4I3T0 & 1.5 & & Guanylate kinase \\
\hline 55 & LMOG_0I263T0 & 1.5 & & Hypothetical protein \\
\hline 56 & LMOG_00427T0 & 1.5 & & DNA topoisomerase IV A subunit \\
\hline
\end{tabular}


Table 4 (Continued)

\begin{tabular}{|c|c|c|c|c|}
\hline S no & Gene & $\begin{array}{l}\text { Fold expression } \\
\text { values }\end{array}$ & $\begin{array}{l}\text { No of gene } \\
\text { transcripts }\end{array}$ & Annotations \\
\hline 57 & LMOG_00440T0 & 1.5 & & tRNA:m(5)U-54 methyltransferase \\
\hline 58 & LMOG_02572T0 & 1.5 & & Hypothetical protein \\
\hline 59 & LMOG_02463T0 & 1.4 & & SMC domain-containing protein \\
\hline 60 & LMOG_01855T0 & 1.4 & & Translation elongation factor $\mathrm{G}$ \\
\hline 61 & LMOG_03II0T0 & 1.4 & & gp54 \\
\hline 62 & LMOG_00436T0 & 1.4 & & Heat shock protein HsIVU ATPase subunit HsIU \\
\hline 63 & LMOG_00490T0 & 1.4 & & Excinuclease $A B C C$ subunit \\
\hline 64 & LMOG_00774T0 & 1.4 & & Hypothetical protein \\
\hline 65 & LMOG_00263T0 & 1.3 & & Penicillin-binding protein \\
\hline 66 & LMOG_00446T0 & 1.3 & & Signal peptidase I \\
\hline 67 & LMOG_02I70T0 & 1.3 & & Translocase subunit secA 2 \\
\hline 68 & LMOG_01003T0 & 1.3 & & Hydrolase \\
\hline 69 & LMOG_00II2TO & 1.3 & & N-6DNAmethylase \\
\hline 70 & LMOG_0I888T0 & 1.3 & & $30 \mathrm{~S}$ ribosomal protein $\mathrm{SI}$ \\
\hline 7I & LMOG_03066T0 & 1.3 & & 4-(cytidine 5'-diphospho)-2-C-methyl-D-erythritol kinase \\
\hline 72 & LMOG_00043T0 & 1.3 & & Helicase \\
\hline 73 & LMOG_02806T0 & 1.3 & & Beta-glucoside-specific PTS system IIA component \\
\hline 74 & LMOG_02765T0 & 1.3 & & ATP-dependent DNA helicase PcrA \\
\hline 75 & LMOG_00384T0 & 1.3 & & YlxP \\
\hline 76 & LMOG_00378T0 & 1.3 & & Polyribonucleotide nucleotidyltransferase \\
\hline 77 & LMOG_0044IT0 & 1.3 & & DNA topoisomerase I \\
\hline 78 & LMOG_02I45T0 & 1.3 & & $A B C$ transporter \\
\hline 79 & LMOG_02 I40T0 & 1.3 & & Transcriptional regulator \\
\hline 80 & LMOG_0I484T0 & 1.3 & & Phage holin \\
\hline 81 & LMOG_02766T0 & 1.3 & & DNA ligase NAD-dependent \\
\hline 82 & LMOG_02I46T0 & 1.3 & & Transcriptional regulator \\
\hline 83 & LMOG_024I7T0 & 1.3 & & SsrA-binding protein \\
\hline 84 & LMOG_0I884T0 & 1.3 & & 50 S ribosomal protein $\mathrm{L} 22$ \\
\hline 85 & LMOG_00I0IT0 & 1.3 & & Aminotransferase \\
\hline 86 & LMOG_0I890T0 & 1.3 & & 50 S ribosomal protein L24 \\
\hline 87 & LMOG_02589T0 & 1.3 & & $50 \mathrm{~S}$ ribosomal protein LII \\
\hline 88 & LMOG_0I489T0 & 1.3 & & Hypothetical protein \\
\hline 89 & LMOG_02594T0 & 1.2 & & RNA polymerase sigma-30 factor \\
\hline 90 & LMOG_0I879T0 & 1.2 & & $50 S$ ribosomal protein $\mathrm{L} 3$ \\
\hline 91 & LMOG_01889T0 & 1.2 & & 50 S ribosomal protein LI4 \\
\hline 92 & LMOG_0I449T0 & 1.2 & & Hypothetical protein \\
\hline 93 & LMOG_01949T0 & 1.2 & & Sigma54-associated activator ManR \\
\hline 94 & LMOG_03270T0 & 1.2 & & Lysyl-tRNA synthetase \\
\hline 95 & LMOG_0I490T0 & 1.2 & & Hypothetical protein \\
\hline 96 & LMOG_03II3T0 & 1.2 & & Predicted protein \\
\hline 97 & LMOG_0I483T0 & 1.2 & & $\mathrm{~N}$-acetylmuramoyl-L-alanine amidase \\
\hline 98 & LMOG_002I2T0 & 1.2 & & Hypothetical protein \\
\hline 99 & LMOG_00456T0 & 1.2 & & Helix-turn-helix domain-containing protein \\
\hline 100 & LMOG_03 I25T0 & 1.2 & & Phage capsid protein \\
\hline 101 & LMOG_00045T0 & 1.2 & & STAS domain-containing protein \\
\hline 102 & LMOG_03I3IT0 & 1.2 & & gP/3 \\
\hline 103 & LMOG_02605T0 & 1.2 & & DNA repair protein RadA \\
\hline 104 & LMOG_00395T0 & 1.2 & & Di-trans,poly-cis-decaprenylcistransferase \\
\hline 105 & LMOG_00I53T0 & 1.2 & & Ribonuclease \\
\hline 106 & LMOG_0I319T0 & 1.2 & & TPR domain-containing protein \\
\hline 107 & LMOG_03 I 20T0 & 1.2 & & Phage terminase small subunit \\
\hline 108 & LMOG_03।30T0 & 1.2 & & Major tail shaft protein \\
\hline 109 & LMOG_02588T0 & 1.2 & & $50 \mathrm{~S}$ ribosomal protein $\mathrm{LI}$ \\
\hline 110 & LMOG_03II7T0 & 1.2 & & gp65 \\
\hline 111 & LMOG_00695T0 & 1.2 & & Zn-dependent hydrolase \\
\hline 112 & LMOG_0I488T0 & I.I & & Hypothetical protein \\
\hline
\end{tabular}


Table 4 (Continued)

\begin{tabular}{|c|c|c|c|c|}
\hline S no & Gene & $\begin{array}{l}\text { Fold expression } \\
\text { values }\end{array}$ & $\begin{array}{l}\text { No of gene } \\
\text { transcripts }\end{array}$ & Annotations \\
\hline 113 & LMOG_01896T0 & 1.1 & & $30 \mathrm{~S}$ ribosomal protein $\mathrm{S} 5$ \\
\hline 114 & LMOG_00255T0 & I.I & & zurR \\
\hline 115 & LMOG_005I2T0 & 1.1 & & Transcriptional regulator \\
\hline 116 & LMOG_00I72T0 & 1.1 & & Adenine phosphoribosyltransferase \\
\hline 117 & LMOG_00213T0 & 1.1 & & lojap protein I55 \\
\hline 118 & LMOG_03I23T0 & 1.1 & & Minor capsid protein \\
\hline 119 & LMOG_00383T0 & I.I & & Ribosome-binding factor $A$ \\
\hline 120 & LMOG_00373T0 & I.I & & 5-formyltetrahydrofolate cyclo-ligase \\
\hline 121 & LMOG_03I56T0 & 1.1 & & Rrf2 family protein \\
\hline 122 & LMOG_03109T0 & 1.1 & & Hypothetical protein \\
\hline 123 & LMOG_0II95T0 & 1.1 & & Cell division protein FtsA \\
\hline 124 & LMOG_01852T0 & I.I & & $30 \mathrm{~S}$ ribosomal protein $\mathrm{SI} 2$ \\
\hline 125 & LMOG_00408T0 & I.I & & Cell division suppressor protein yneA \\
\hline 126 & LMOG_00209T0 & I.I & & Shikimate 5-dehydrogenase \\
\hline 127 & LMOG_00500T0 & 1.1 & & $A B C$ transporter permease \\
\hline 128 & LMOG_00I7ITO & 1.1 & & Single-stranded-DNA-specific exonuclease rec] \\
\hline 129 & LMOG_03।39T0 & I.I & & Short tail fiber \\
\hline 130 & LMOG_00102T0 & 1.1 & & Thiamine biosynthesis/tRNA modification protein Thil \\
\hline 131 & LMOG_0I90IT0 & I.I & & Hypothetical protein \\
\hline 132 & LMOG_0I495T0 & I.I & & Prophage LambdaLm0I \\
\hline 133 & LMOG_03I22T0 & 1.0 & & Phage portal protein \\
\hline 134 & LMOG_03I2ITO & 1.0 & & Phage terminase large subunit \\
\hline 135 & LMOG_02452T0 & 1.0 & & Hypothetical protein \\
\hline 136 & LMOG_02335T0 & 1.0 & & MreB-like protein \\
\hline 137 & LMOG_03308T0 & 1.0 & & Translation initiation factor IF-3 \\
\hline 138 & LMOG_01869T0 & 1.0 & & Heptaprenyl diphosphate synthase component II \\
\hline 139 & LMOG_00486T0 & 1.0 & 47 & Ribonuclease $\mathrm{PH}$ \\
\hline 140 & LMOG_00240T0 & 1.0 & & DNA repair protein $\mathrm{RecO}$ \\
\hline 141 & LMOG_01892T0 & 1.0 & & 30 S ribosomal protein $\mathrm{SI} 4 \mathrm{p} / \mathrm{S} 29 \mathrm{e}$ \\
\hline 142 & LMOG_00I32T0 & 1.0 & & Dephospho-CoA kinase \\
\hline 143 & LMOG_02609T0 & 1.0 & & Transcriptional regulator CtsR \\
\hline 144 & LMOG_00437T0 & 1.0 & & ATP-dependent protease hsIV \\
\hline 145 & LMOG_0I482TO & 0.9 & & Hypothetical protein \\
\hline 146 & LMOG_00074T0 & 0.9 & & Phosphotransferase enzyme family protein \\
\hline 147 & LMOG_03I42T0 & 0.9 & & Phage holin \\
\hline 148 & LMOG_03090T0 & 0.9 & & gp37 \\
\hline 149 & LMOG_03I26T0 & 0.9 & & gp8 \\
\hline 150 & LMOG_0I486T0 & 0.9 & & Hypothetical protein \\
\hline 151 & LMOG_00759T0 & 0.9 & & Inorganic polyphosphate/ATP-NAD kinase \\
\hline 152 & LMOG_02356T0 & 0.9 & & Cell division ATP-binding protein FtsE \\
\hline 153 & LMOG_0050IT0 & 0.9 & & ABC transporter ATP-binding protein \\
\hline 154 & LMOG_006IITO & 0.9 & & Hypothetical protein \\
\hline 155 & LMOG_00703T0 & 0.9 & & Ribonucleic acid-binding domain-containing protein \\
\hline 156 & LMOG_02007T0 & 0.9 & & Hypothetical protein \\
\hline 157 & LMOG_03273T0 & 0.9 & & Dihydroneopterin aldolase \\
\hline 158 & LMOG_00804T0 & 0.9 & & $A B C$ transporter permease \\
\hline 159 & LMOG_00I83T0 & 0.9 & & ATPase \\
\hline 160 & LMOG_01902T0 & 0.9 & & Translation initiation factor IF-I \\
\hline 161 & LMOG_03238T0 & 0.9 & & $50 \mathrm{~S}$ ribosomal protein $\mathrm{L} 35$ \\
\hline 162 & LMOG_03034T0 & 0.9 & & tilS/hprT \\
\hline 163 & LMOG_03070T0 & 0.9 & & YabE protein \\
\hline 164 & LMOG_00I00T0 & 0.9 & & Septation ring formation regulator EzrA \\
\hline 165 & LMOG_007I7T0 & 0.9 & & Hypothetical protein \\
\hline 166 & LMOG_0I264T0 & 0.9 & & Pentitol PTS system enzyme II B component \\
\hline 167 & LMOG_00445T0 & 0.9 & & Ribosome biogenesis GTP-binding protein YlqF \\
\hline
\end{tabular}


Table 4 (Continued)

\begin{tabular}{|c|c|c|c|c|}
\hline S no & Gene & $\begin{array}{l}\text { Fold expression } \\
\text { values }\end{array}$ & $\begin{array}{l}\text { No of gene } \\
\text { transcripts }\end{array}$ & Annotations \\
\hline 168 & LMOG_0I378T0 & 0.9 & & DegV family protein \\
\hline 169 & LMOG_0327IT0 & 0.8 & & Dihydrouridine synthase \\
\hline 170 & LMOG_00220T0 & 0.8 & & GTP-binding protein LepA \\
\hline 171 & LMOG_000IITO & 0.8 & & Hydrolase \\
\hline 172 & LMOG_02658T0 & 0.8 & & Transcriptional regulator \\
\hline 173 & LMOG_0I49IT0 & 0.8 & & Hypothetical protein \\
\hline 174 & LMOG_0229IT0 & 0.8 & & Hypothetical protein \\
\hline 175 & LMOG_03065T0 & 0.8 & & Hypothetical protein \\
\hline 176 & LMOG_00404T0 & 0.8 & & Predicted protein \\
\hline 177 & LMOG_03I24T0 & 0.8 & & Scaffolding protein \\
\hline 178 & LMOG_02655T0 & 0.8 & & PRD/PTS system IIA 2 domain-containing regulatory protein \\
\hline 179 & LMOG_00339T0 & 0.8 & & DNA repair protein $\mathrm{RecN}$ \\
\hline 180 & LMOG_0I302T0 & 0.8 & & Ribosome-associated GTPase EngA \\
\hline 181 & LMOG_02304T0 & 0.8 & & Glycosyltransferase \\
\hline 182 & LMOG_00I22T0 & 0.8 & & Acetyl-CoA carboxylase carboxyl transferase alpha subunit \\
\hline 183 & LMOG_00218T0 & 0.8 & & DNA polymerase III delta subunit \\
\hline 184 & LMOG_02522T0 & 0.8 & & Hypothetical protein \\
\hline 185 & LMOG_0I494T0 & 0.8 & & Prophage LambdaLm0I \\
\hline
\end{tabular}

from the genes that were upregulated specifically at fixed time intervals, we also report on the genes that showed a pattern of fluctuating levels of upregulation. Some genes were either not upregulated or minimally upregulated at 4 hours of growth, but were increasingly upregulated after 12 and 24 hours. Similarly, a group of genes was markedly upregulated at 4 hours, but was downregulated after 12 and 24 hours.

An interesting observation in this respect is the expression pattern for glycoproteins, which have been reported to have varied functions, ranging from cell adhesion to cellto-cell signaling. ${ }^{30,31}$ Glycoprotein expression, as observed in our study, is of significance for the reason that a set of 12 glycoproteins showed an ascending pattern of upregulation over time. For instance, gp49, a putative gene transcript with an unknown function, is expressed with an ascending

Table 5 Number of genes upregulated with a ascending pattern from 4 to 24 hours of biofilms growth as compared to the 24 hours broth culture of $L$. moncytogenes J0I6I.

\begin{tabular}{lll}
\hline Fold variation & Number of genes & \% of genes \\
\hline More than 6 fold variation & $\mathrm{I}$ & 0.1 \\
More than 5 fold variation & 8 & $\mathrm{I}$ \\
More than 4 fold variation & 20 & 2.4 \\
More than 3 fold variation & 44 & 5.3 \\
More than 2 fold variation & 86 & 10.3 \\
More than I fold variation & 330 & 39.5 \\
Less than I fold variation & 347 & 41.5 \\
\hline
\end{tabular}

order of more than six-fold variation from 4 to 24 hours. The glycoprotein expression pattern specifically in biofilm but not in broth culture signifies a clear role of glycoproteins in biofilms. Glycoproteins have been reported to play a role in cell-to-cell signaling and communication. The ascending trend of glycoprotein expression in biofilm is suggestive of a similar role of cell-to-cell communication/ signaling. Cell-to-cell communication for quorum sensing in biofilms is critical. Though we report specific genes that were upregulated at a particular time of biofilm growth, we could not fully understand or implicate the role of these genes in biofilm formation. Knockout studies would help to clarify the role of these genes further.

\section{Acknowledgments}

We sincerely thank Sant Prakash and VG Das for their support and encouragement. We also express our sincere gratitude to the Agriculture Research Services, United States Department of Agriculture, for providing us with the L. monocytogenes J0161 strain and Genotypic Technology Pvt Ltd for their support. We are indebted to Mohamed Aiyaz and Madhan Tirumalai for their suggestions and comments on the manuscript. We also wish to acknowledge the support of the Ministry of Science and Technology, Government of India through the Department of Science and Technology FIST program, which provided us with the laboratory facilities needed to undertake this work. 
Table 6 List of genes and their annotations upregulated with a ascending pattern from 4 to 24 hours of biofilms growth as compared to the 24 hours broth culture of L. monocytogenes J016I

\begin{tabular}{|c|c|c|}
\hline Gene & $\begin{array}{l}\text { Variation (ascending) in fold expression } \\
\text { from } 4 \text { to } 24 \text { hours of biofilm }\end{array}$ & Gene description \\
\hline LMOG_03I04T0 & Above 6.0 & gp49 \\
\hline LMOG_03I02T0 & 5.0 to 6.0 & Hypothetical protein \\
\hline LMOG_02195T0 & & Magnesium transporter \\
\hline LMOG_0I46IT0 & & Zinc $A B C$ transporter \\
\hline LMOG_03098T0 & & gp43 \\
\hline LMOG_03I0IT0 & & Predicted protein \\
\hline LMOG_03IIIT0 & & Hypothetical protein \\
\hline LMOG_03I29T0 & & gPII \\
\hline LMOG_03।I5T0 & & gp63 \\
\hline LMOG_03099T0 & 4.0 to 5.0 & gp44 \\
\hline LMOG_03II3T0 & & Predicted protein \\
\hline LMOG_03097T0 & & gp37 \\
\hline LMOG_03100T0 & & gр39 \\
\hline LMOG_03I06T0 & & Predicted protein \\
\hline LMOG_03II6T0 & & gp64 \\
\hline LMOG_03140T0 & & gp22 \\
\hline LMOG_03133T0 & & gpl5 \\
\hline LMOG_03090T0 & & gp37 \\
\hline LMOG_03।20T0 & & Phage terminase small subunit \\
\hline LMOG_02II4T0 & & Methyltransferase \\
\hline LMOG_0I262T0 & & Hypothetical protein \\
\hline LMOG_03I07T0 & & $\mathrm{gp} 5 \mathrm{I}$ \\
\hline LMOG_02II5T0 & & Rrf2 family protein \\
\hline LMOG_0I386T0 & & YvgZ \\
\hline LMOG_00932T0 & & Spermidine/putrescine import ATP-binding protein potA \\
\hline LMOG_0I462T0 & & Zinc $A B C$ transporter \\
\hline LMOG_01652T0 & & Inner membrane $A B C$ transporter permease $Y c j P$ \\
\hline LMOG_03I22T0 & & Phage portal protein \\
\hline LMOG_01650T0 & & $A B C$-type sugar transport system periplasmic binding protein $Y_{c j N}$ \\
\hline
\end{tabular}

Table 7 Number of genes upregulated with a descending pattern from 4 to 24 hours of biofilms growth as compared to the 24 hours broth culture of L. monocytogenes J016I

\begin{tabular}{lll}
\hline Fold variation & Number of genes & \% of genes \\
\hline More than 6 fold variation & 2 & 0.2 \\
More than 5 fold variation & 6 & 0.7 \\
More than 4 fold variation & 19 & 2.2 \\
More than 3 fold variation & 34 & 4 \\
More than 2 fold variation & 120 & 14.2 \\
More than I fold variation & 296 & 34.9 \\
Less than I fold variation & 370 & 43.7 \\
\hline
\end{tabular}

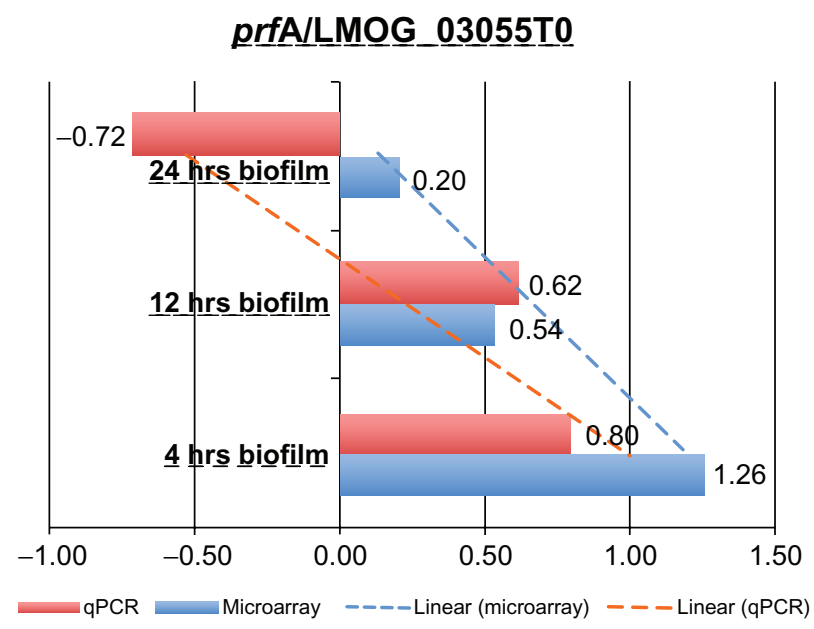

Figure 3 Comparison of expression data of prfA from microarray and qPCR. 
Table 8 List of genes and their annotations upregulated with a descending pattern from 4 to 24 hours of biofilms growth as compared to the 24 hours broth culture of $L$. monocytogenes JO16I

\begin{tabular}{|c|c|c|}
\hline Gene & $\begin{array}{l}\text { Variation (descending) in fold expression } \\
\text { from } 4 \text { to } 24 \text { hours of biofilm formation }\end{array}$ & Gene description \\
\hline LMOG_0268IT0 & Above 6.0 & Fructose-specific IIA PTS system component \\
\hline LMOG_02679T0 & & Fructose-specific PTS system fructose-specific II component \\
\hline LMOG_0I728T0 & 5.0 to 6.0 & Cellobiose-specific PTS system IIA component \\
\hline LMOG_02680T0 & & Fructose-specific PTS system IIB component \\
\hline LMOG_0I844T0 & & Alcohol dehydrogenase \\
\hline LMOG_0I843T0 & & Alcohol dehydrogenase \\
\hline LMOG_0I845T0 & & Ribose 5-phosphate isomerase $B$ \\
\hline LMOG_00557T0 & & Hypothetical protein \\
\hline LMOG_0I848T0 & 4.0 to 5.0 & Ribulose-phosphate 3-epimerase \\
\hline LMOG_01842T0 & & Galactitol-specific PTS enzyme IIC component \\
\hline LMOG_0I839T0 & & PTS system IIA 2 domain-containing protein \\
\hline LMOG_02678T0 & & Alpha-mannosidase \\
\hline LMOG_0I846T0 & & Ribulose-phosphate 3-epimerase \\
\hline LMOG_01215T0 & & Cold shock protein CspB \\
\hline LMOG_0I84IT0 & & Galactitol-specific PTS enzyme IIB component \\
\hline LMOG_00362T0 & & Competence protein ComGA \\
\hline LMOG_01840T0 & & Galactitol-specific PTS system IIA component \\
\hline LMOG_0I729T0 & & ROK family protein \\
\hline LMOG_02677T0 & & PRD/PTS system IIA 2 domain-containing protein \\
\hline LMOG_0II62T0 & & Hypothetical protein \\
\hline LMOG_01996T0 & & Glycosyl hydrolase family I subfamily \\
\hline LMOG_00980T0 & & Hypothetical protein \\
\hline LMOG_0I37IT0 & & DedA family protein \\
\hline LMOG_02000T0 & & D-allulose-6-phosphate 3-epimerase \\
\hline LMOG_0I73IT0 & & Cellobiose-specific PTS system IIB component \\
\hline LMOG_0I094T0 & & Maltose/maltodextrin $A B C$ transporter \\
\hline LMOG_0I732T0 & & Beta-glucosidase \\
\hline
\end{tabular}

Table 9 List of genes unregulated commonly at all the three time intervals

\begin{tabular}{lll}
\hline S no & Gene & Annotation \\
\hline I & LMOG_02396T0 & Clp protease \\
2 & LMOG_0059IT0 & Clp protease \\
3 & LMOG_024IIT0 & Hypothetical protein \\
4 & LMOG_02477T0 & NifU family protein \\
5 & LMOG_00277T0 & Nramp family mn2+/fe2+ transporter \\
6 & LMOG_02607T0 & ATP:guanido phosphotransferase \\
7 & LMOG_00679T0 & Molybdopterin biosynthesis protein \\
& & MoeA \\
8 & LMOG_01005T0 & ATP-dependent chaperone ClpB \\
9 & LMOG_02567T0 & Internalin C2 \\
I0 & LMOG_01012T0 & Transcriptional regulator \\
II & LMOG_02442T0 & ArsC family protein \\
I2 & LMOG_00358T0 & Glycine dehydrogenase \\
I3 & LMOG_02443T0 & Glycine cleavage system H protein \\
I4 & LMOG_01666T0 & Phosphoserine aminotransferase \\
I5 & LMOG_01498T0 & Helix-turn-helix domain-containing \\
& & protein \\
I6 & LMOG_03035T0 & Hypothetical protein \\
I7 & LMOG_00763T0 & Hypothetical protein \\
I8 & LMOG_00674T0 & Molybdenum cofactor biosynthesis \\
& & protein A \\
\hline
\end{tabular}

Table 9 (Continued)

\begin{tabular}{|c|c|c|}
\hline S no & Gene & Annotation \\
\hline 19 & LMOG_00286T0 & Hydroxymethylglutaryl-CoAsynthase \\
\hline 20 & LMOG_0I784T0 & GW repeat-containing protein \\
\hline 21 & LMOG_004IIT0 & LexA repressor \\
\hline 22 & LMOG_00675T0 & $\begin{array}{l}\text { Molybdenum cofactor biosynthesis } \\
\text { protein C }\end{array}$ \\
\hline 23 & LMOG_0I667T0 & $\begin{array}{l}\text { D-isomer specific 2-hydroxy acid } \\
\text { dehydrogenase }\end{array}$ \\
\hline 24 & LMOG_0I70IT0 & $\begin{array}{l}\text { Chromosome partitioning protein parA/ } \\
\text { Sporulation initiation inhibitor } \\
\text { protein Soj }\end{array}$ \\
\hline 25 & LMOG_0I0I3T0 & OsmC/Ohr family protein \\
\hline 26 & LMOG_00309T0 & $\begin{array}{l}\text { 3-ketoacyl-(acyl-carrier-protein) } \\
\text { reductase }\end{array}$ \\
\hline 27 & LMOG_00287T0 & Acetyl-CoA acetyltransferase \\
\hline 28 & LMOG_024I2T0 & Carboxylesterase \\
\hline 29 & LMOG_00049T0 & $\begin{array}{l}\text { Muramoyl-tetrapeptide } \\
\text { carboxypeptidase family }\end{array}$ \\
\hline 30 & LMOG_0032IT0 & Isopentenyl-diphosphate delta-isomerase \\
\hline 31 & LMOG_0I783T0 & Peptidoglycan bound protein \\
\hline 32 & LMOG_00234T0 & HDIG domain-containing protein \\
\hline 33 & LMOG_00237T0 & Cytidine deaminase \\
\hline 34 & LMOG_00225T0 & Co-chaperone GrpE \\
\hline
\end{tabular}


Table 9 (Continued)

\begin{tabular}{ll}
\hline S no & Gene \\
\hline 35 & LMOG_00667T
\end{tabular}

36 LMOG_0I759T0

37 LMOG_00224TO

38 LMOG_00304T0

39 LMOG_00236T0

40 LMOG_0II70T0

4I LMOG_0066IT0

42 LMOG_0I0I8T0

43

44

45

46

47

48

49

50

51

52

53

54

LMOG 02468TO

LMOG_02473T0

LMOG_02386T0

LMOG_00946T0

LMOG_00233T0

LMOG_00676T0

LMOG_00322T0

LMOG_01573T0

LMOG 0I006T0

LMOG_0247ITO

LMOG_01702TO

LMOG_02604T0

LMOG_00I33T0

LMOG_00325T0

LMOG 00843T0

LMOG_00I30T0

LMOG_00I28T0

LMOG_02374T0

LMOG 0I572T0

LMOG_00I00T0

LMOG_00235T0

LMOG_00824T0

LMOG_00095T0

LMOG_00662T0

LMOG_0I0I9T0

LMOG_02999T0

LMOG_00623T0

LMOG_00694T0

LMOG_00326T0

LMOG_0217ITO

LMOG_00448T0

LMOG 00406T0

LMOG_00048T0

LMOG_0009IT0

LMOG_002IITO

LMOG_0I200T0

LMOG_01622T0

LMOG_007I3T0

LMOG_00840T0

LMOG_00I3ITO

LMOG_02455T0

LMOG_0037IT0
Annotation

Pyruvate dehydrogenase complex,

El component, pyruvate dehydrogenase beta subunit

CBS domain-containing protein

Heat-inducible transcription

repressor HrcA

RecA protein

Diacylglycerol kinase

Protoheme IX farnesyltransferase

Thioredoxin family protein

Oligopeptide $A B C$ transporter

oligopeptide-binding protein
Hypothetical protein

HAD-superfamily subfamily IIA hydrolase

Thioredoxin-disulfide reductase

PhoH family protein

Molybdopterin converting factor

subunit I

Hypothetical protein

Accessory regulator protein $\mathrm{C}$

Phosphoglycerate mutase

Ser/Thr protein phosphatase

Partition protein ParB homolg

Pin/tram domain-containing protein

Transcriptional regulator $\mathrm{NrdR}$

Hypothetical protein

CopG family transcriptional regulator

Methylcitrate synthase

Excinuclease $A B C B$ subunit

Accessory regulator protein $A$

Septation ring formation regulator EzrA

Hypothetical protein

Hypothetical protein

Hypothetical protein

Hypothetical protein

Oligopeptide $A B C$ transporter permease

Hypothetical protein

PTS system IIB component

Hypothetical protein

OxaA-like protein

p60

Signal peptidase I

Transketolase

DNA-3-methyladenine glycosylase I

General stress protein

Nicotinate nucleotide

adenylyltransferase

S4 domain-containing protein

Mevalonate kinase

Transcriptional regulator

RsbS

Formamidopyrimidine-DNA glycosylase

Carbon-sulfur lyase

Hypothetical protein
HAD-superfamily hydrolase

DNA polymerase I
Table 9 (Continued)

\begin{tabular}{|c|c|c|}
\hline S no & Gene & Annotation \\
\hline 85 & LMOG_0I574T0 & Accessory regulator protein $D$ \\
\hline 86 & LMOG_003I2T0 & $A B C$ transport system permease \\
\hline 87 & LMOG_0II36T0 & Lipase \\
\hline 88 & LMOG_02347T0 & Transcriptional regulatory protein DegU \\
\hline 89 & LMOG_00020T0 & Peptidoglycan linked protein \\
\hline 90 & LMOG_00302T0 & Hypothetical protein \\
\hline 91 & LMOG_0I907T0 & 50 S ribosomal protein LI7 \\
\hline 92 & LMOG_00839T0 & Serine/threonine-protein kinase rsbT \\
\hline 93 & LMOG_003I5T0 & Surface antigen \\
\hline 94 & LMOG_0030IT0 & Acetyltransferase \\
\hline 95 & LMOG_0I28IT0 & Fur protein \\
\hline 96 & LMOG_00842T0 & PemK family transcriptional regulator \\
\hline 97 & LMOG_00665T0 & Dihydrolipoyl dehydrogenase \\
\hline 98 & LMOG_02735T0 & Hypothetical protein \\
\hline 99 & LMOG_00663T0 & Lactate/malate dehydrogenase \\
\hline 100 & LMOG_0II72T0 & Regulatory protein YlbF \\
\hline 101 & LMOG_0I26IT0 & DNApolymerase IV \\
\hline 102 & LMOG_0II73T0 & Hypothetical protein \\
\hline 103 & LMOG_000IITO & Hydrolase \\
\hline 104 & LMOG_00I88T0 & TPR domain-containing protein \\
\hline \multirow[t]{2}{*}{105} & LMOG_03307T0 & dTDP-4-dehydrorhamnose \\
\hline & & 3,5-epimerase \\
\hline 106 & LMOG_02392T0 & Hypothetical protein \\
\hline 107 & LMOG_02474T0 & Acetyltransferase \\
\hline 108 & LMOG_0084IT0 & Modulator protein RsbR \\
\hline 109 & LMOG_00083T0 & tRNA binding domain-containing protein \\
\hline 110 & LMOG_0077IT0 & Glucosamine-6-phosphate isomerase \\
\hline 111 & LMOG_03305T0 & $\begin{array}{l}\text { Minor teichoic acids biosynthesis } \\
\text { protein GgaB }\end{array}$ \\
\hline 112 & LMOG_0I099T0 & Hypothetical protein \\
\hline 113 & LMOG_02767T0 & CamS sex pheromone cAM37 \\
\hline 114 & LMOG_0II88T0 & Cell division protein ftsL \\
\hline 115 & LMOG_00389T0 & Hypothetical protein \\
\hline 116 & LMOG_00349T0 & General stress protein \\
\hline 117 & LMOG_0257IT0 & $\begin{array}{l}\text { DNA-directed RNA polymerase beta } \\
\text { subunit }\end{array}$ \\
\hline 118 & LMOG_0277IT0 & Hypothetical protein \\
\hline 119 & LMOG_0I340T0 & Pantoate-beta-alanine ligase \\
\hline 120 & LMOG_00204T0 & Hypothetical protein \\
\hline$|2|$ & LMOG_00207T0 & HAD superfamily phosphatase \\
\hline \multirow[t]{2}{*}{122} & LMOG_00699T0 & Potassium transport system \\
\hline & & NAD-binding component \\
\hline 123 & LMOG_0I62IT0 & Diphosphomevalonate decarboxylase \\
\hline 124 & LMOG_00802T0 & Sulfatase \\
\hline 125 & LMOG_00299T0 & YmcA \\
\hline 126 & LMOG_02353T0 & Preprotein translocase SecA subunit \\
\hline 127 & LMOG_00191T0 & DNA-binding response regulator \\
\hline 128 & LMOG_02456T0 & $\begin{array}{l}\text { NifU family SUF system FeS assembly } \\
\text { protein }\end{array}$ \\
\hline 129 & LMOG_00823T0 & Hypothetical protein \\
\hline
\end{tabular}

(Continued) 


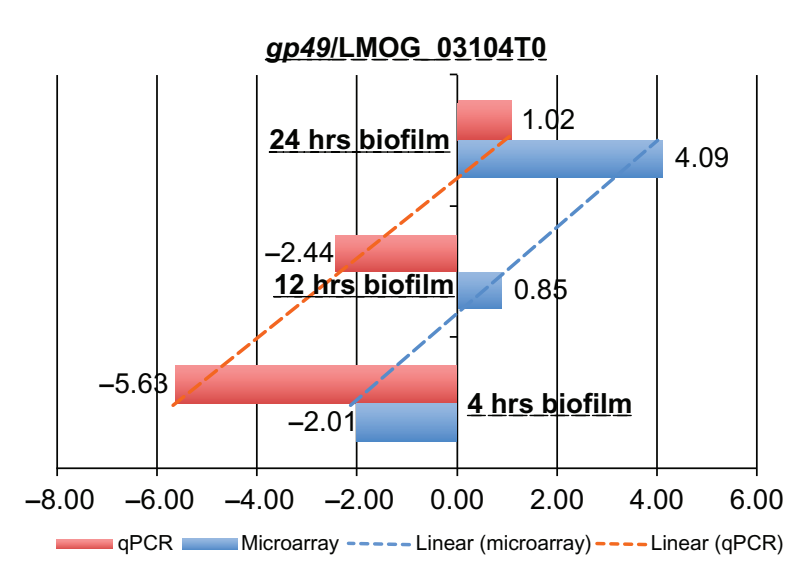

Figure 4 Comparison of expression data of gp49 from microarray and qPCR.

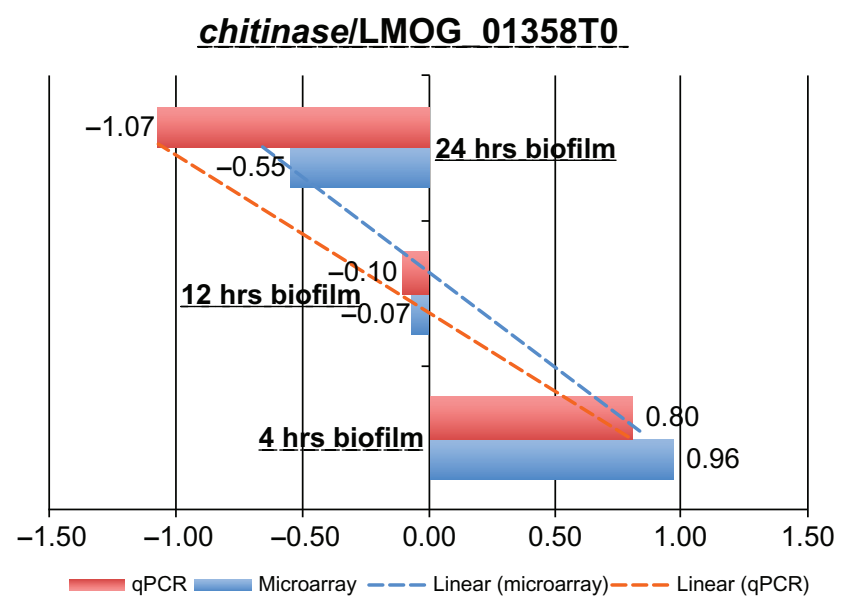

Figure 5 Comparison of expression data of chitinase from microarray and qPCR.

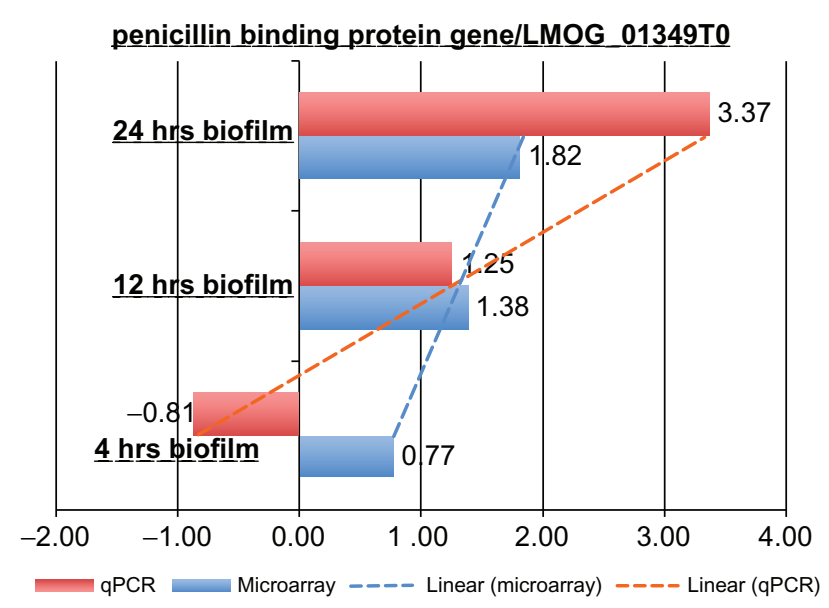

Figure 6 Comparison of expression data of penicillin binding protein from microarray and $\mathrm{qPCR}$.

\section{Disclosure}

The authors report no conflicts of interest in this work.

\section{References}

1. Doyle MP, Beuchat LR, Montville TJ, editors. Food Microbiology: Fundamentals and Frontiers. 2nd ed. Washington, DC: American Society for Microbiology; 2001.

2. Adak GK, Long SM, O'Brien SJ. Trends in indigenous foodborne disease and deaths, England and Wales: 1992 to 2000. Gut. 2002;51:832-841.

3. Fleming DW, Cochi SL, MacDonald KL, et al. Pasteurized milk as a vehicle of infection in an outbreak of Listeriosis. $N$ Engl $J$ Med. 1985;312:404-407.

4. Goulet V, Jacquet C, Vaillant V, et al. Listeriosis from consumption of raw-milk cheese. Lancet. 1995;345:1581-1582.

5. Ho JL, Shands KN, Friedland G, Eckind P, Fraser DW. An outbreak of type $4 \mathrm{~b}$ Listeria monocytogenes infection involving patients from eight Boston hospitals. Arch Intern Med. 1986;146:520-524.

6. Linnan MJ, Mascola L, Lou XD, et al. Epidemic listeriosis associated with Mexican-style cheese. N Engl J Med. 1988;319:823-828.

7. McLauchlin JS. Human listeriosis in Britain. Epidemiol Infect. 1967;104:181-189.

8. Mead PS, Slutsker L, Dietz V, et al. Food-related illness and death in the United States. Emerg Infect Dis. 1999;5:607-625.

9. Nguyen MH, Yu VL. Listeria monocytogenes peritonititis in cirrhotic patients. Dig Dis Sci. 1994;39:215-218.

10. Riedo FX, Pinner RW, Tosca ML, et al. A point-source foodborne listeriosis outbreak: documented incubation period and possible and possible mild illness. J Infect Dis. 1994;170:693-696.

11. Schlech WI, Lavigne PM, Bortolussi RA, et al. Epidemic listeriosis evidence of transmission by food. N Engl J Med. 1983;308:203-206.

12. Schwartz B, Ciesielski CA, Broome CV; TLS Group. Association of sporadic listeriosis with consumption of uncooked hotdogs and undercooked chicken. Lancet. 1988;2:779-782.

13. Donlan RM. Biofilms: microbial life on surfaces. Emerg Infect Dis. 2002;8:881-890.

14. Jeong D, Frank J. Growth of Listeria monocytogenes at $10^{\circ} \mathrm{C}$ in biofilms with microorganisms isolated from meat and dairy processing environments. J Food Prot. 1994;57:576-586.

15. Kornacki JL, Gurtler J. Incidence and control of Listeria in food processing facilities. In: Ryser ET, Marth EH, editors. Listeria, Listeriosis and Food Safety. 3rd ed. New York, NY: CRC Press Inc; 2007.

16. Kumar CG, Anand SK. Significance of microbial biofilms in food industry: a review. Int J Food Microbiol. 1998;42:9-27.

17. Lewis K. Riddle of biofilm resistance. Antimicrob Agents Chemother. 2001;5:999-1007.

18. Mah TF, O'Toole GA. Mechanisms of biofilm resistance to antimicrobial agents. Trends Microbiol. 2001;9:34-39.

19. Moreto T, Langsrud S. Listeria monocytogenes: biofilm formation and persistence in food-processing environments. Biofilms. 2004;1:107-121.

20. Merritt JH, Kadouri DE, O’Toole GA. Growing and analysing static biofilms. Curr Protoc Microbiol. 2011.

21. Chavant P, Martinie B, Meylheuc T, Fontaine MNB, Hebraud M. Listeria monocytogenes LO28: surface physicochemical properties and ability to form biofilms at different temperatures and growth phases. Appl Environ Microbiol. 2002;68:728-737.

22. Beresford M, Andrew P, Shama G. Listeria monocytogenes adheres to many materials found in food-processing environments. $J \mathrm{Appl}$ Microbiol. 2001;90:1000-1005.

23. Boles BR, Singh PK. Endogenous oxidative stress produces diversity and adaptability in biofilm communities. Proc Natl Acad Sci U S A. 2008;105:12503-12508.

24. Zeller T, Klug G. Thioredoxins in bacteria: Functions in oxidative stress response and regulation of thioredoxin genes. Naturwissenschaften. 2006;93:259-266.

25. Yi S, Sahni N, Daniels KJ, et al. Alternative mating type configurations $(\mathrm{a} / \alpha$ versus $\mathrm{a} / \mathrm{a}$ or $\alpha / \alpha)$ of Candida albicans result in alternative biofilms regulated by different pathways. PLoS Biol. 2011;9:1-17. 
26. Hautefort I, Thompson A, Eriksson-Ygberg S, et al. During infection of epithelial cells Salmonella enterica serovar Typhimurium undergoes a time-dependent transcriptional adaptation that results in simultaneous expression of three type 3 secretion systems. Cell Microbiol. 2008; 10:958-984.

27. Chan YC, Raengpradub S, Boor KJ, Wiedmann M. Microarray-based characterization of the Listeria monocytogenes cold regulon in log-and stationary-phase cells. Appl Environ Microbiol. 2007;73:6484-6498.

28. Drenkard E. Antimicrobial resistance of Pseudomonas aeruginosa biofilms. Microbes Infect. 2003;5:1213-1219.
29. Lemon KP, Freitag NE, Kolter R. The virulence regulator PrfA promotes biofilm formation by Listeria monocytogenes. $J$ Bacteriol. 2010;192:3969-3976.

30. Messner P. Bacterial glycoproteins. Glycoconj J. 1997;14:3-11.

31. Upreti RK, Kumar M, Shankar V. Bacterial glycoproteins: Functions, biosynthesis and applications. Proteomics. 2003;3:363-379.

\section{Publish your work in this journal}

Advances in Genomics and Genetics is an international, peer reviewed, open access journal that focuses on new developments in characterizing the human and animal genome and specific gene expressions in health and disease. Particular emphasis will be given to those studies that elucidate genes, biomarkers and targets in the development of new or improved therapeutic interventions. The journal is characterized by the rapid reporting of reviews, original research, methodologies, technologies and analytics in this subject area. The manuscript management system is completely online and includes a very quick and fair peer-review system. Visit http://www.dovepress.com/ testimonials.php to read real quotes from published authors.

Submit your manuscript here: http://www.dovepress.com/advances-in-genomics-and-gene-expression-journal 